\title{
An Assessment of Tribological Characteristics under different Operating Condition
}

\author{
Bougoffa M. Seyf Eddine ${ }^{1, *}$, T. Sayah', Bachir Bey M. Nabil', Benouali Chahrazed ${ }^{1}$ \\ ${ }^{1}$ Laboratory of Materials Technology, Department of Materials Science, University of Science and Technology Houari \\ Boumediene, Bp 32 El Alia 16111 Bab Ezzouar, Algiers, Algeria
}

*Corresponding author: E-mail: mbougoffa@usthb.dz

DOI: 10.5185/amlett.2020.021478

The paper evaluates and compares the friction and wear behavior of SAE-AISI 1060 steel and brass (CuZn37Pb2) at different initial surface roughness and normal load using pin-on-disc test. Tribological behavior of studied materials was analyzed in detail. Variation of coefficient of friction at different initial surface roughness and normal load has been correlated with wear loss, wear rate, track width. Experiments are carried out in normal load 3-5-8-10 N, sliding speed $0.24-0.35 \mathrm{~m} / \mathrm{s}$ and $0.48 \mathrm{~m} / \mathrm{s}$, wear track diameter 4-6-8-10 mm. Results show that friction coefficient, wear loss and wear rate of steel increase with track width at high initial surface roughness and normal load. For brass friction coefficient decreases with the increase of normal load. On the other hand, it is also found that wear loss, wear rate and track width increase with sliding distance. Microscopic of worn surfaces for each alloy were carried out and compared.

\section{Introduction}

The alloys studied SAE-AISI 1060 steel and brass $(\mathrm{CuZn} 37 \mathrm{~Pb} 2)$ are widely used in applications where a high resistance to wear and stand high forming stresses. It is known that the tribological behavior of the materials in contact depends on several tribological parameters which are interdependent on each other such as the normal force, the sliding speed, the hardness of the material, etc. [1-8].

Understanding and predicting the tribological behavior of materials under different operating conditions is one of the major concerns in today's industry applications. Study the effect of different parameters that control the friction and wear behavior, especially normal load, sliding speed, and initial surface roughness is necessary. It is true that many experiments have been conducted to discover more properties of steel and brass, but the friction and wear behavior of these materials is not clearly defined, this makes the study of friction and wear at the laboratory rather specific, since wear is an evolutionary and irreversible phenomenon; each state of a system permanently destroys the previous state, so it is very difficult, if not impossible, to reconstruct the past from the observation of a degradation. There are many tribological test methods [9].

The most common for basic studies use laboratory tribometers: pin-on-disc test, cylinder block test. Moreover, the tribological behavior of the pairs of materials also depends on the films present at the interface [10]. The main objective of this study is to evaluate the tribological behavior of steel and brass by conducting pinon-disc test, with different normal load, sliding speed and initial surface roughness in order to contribute to improving performance and quality in industry.

\section{Experimental method}

\section{Experimental device and materials}

Dry sliding wear tests were carried out on a tribometer brand $\mathrm{CSM}$ at a regulated temperature $\left(25^{\circ} \mathrm{C}\right)$. Variation of coefficient of friction according to the three parameters of time, displacement and the number of turns was determined.

The materials chosen as a disc in this investigation are Steel and brass. While 100Cr6 martensitic steel (52100) was used as the ball material. Usually martensitic stainless steels used for applications where high mechanical performance is desired [11-13]. The balls were utilized in the soft, as-received condition, while the samples were polished using 240, 600 and 1200-grit silicon carbide papers to achieve the final properties and surface finish (Table 1).

At the end of the tests, the worn surfaces of the test specimens were analyzed using scanning electron microscope techniques to characterize the wear modes, resulting surface damage and wear volume. Twodimensional surface profiles were measured across the wear track at four positions for each track diameter.

Table. 1. Summary of materials tested.

\begin{tabular}{c|c|c|c}
\hline Specimen & Material & Hardness & $\begin{array}{c}\text { Surface } \\
\text { Roughness } \\
\text { Ra[ } \boldsymbol{\mu m}]\end{array}$ \\
\hline \multirow{2}{*}{ Disc } & SAE-AISI 1060 steel & $183 \pm 0.5 \mathrm{HB}$ & $0.88-1.62-2.18$ \\
\cline { 2 - 4 } & Brass CuZn37Pb2 & $64 \pm 0.5 \mathrm{HB}$ & $0.48-0.76-1.33$ \\
\hline Ball & AISI-52100 Steel & $780 \mathrm{HV} 30$ & $0.09 \pm 0.01$ \\
\hline
\end{tabular}




\section{Advanced Materials Letters www. vbripress.com/aml}

\section{Experimental procedure}

Wear loss of the sample is considered as a wear parameter evolving in function of time. To determine $(\Delta \mathrm{m})$, the samples were weighed before and after the tests using of an Ohaus CP214 weighing precision balance $0.0001 \mathrm{~g}$ digital scale. The wear loss was converted to volume loss (VL) using the density of steel, which is $7.85 \mathrm{~g} / \mathrm{cm} 3$. And the density of brass $8.44 \mathrm{~g} / \mathrm{cm} 3$. The wear rate (WR) for the specimens were calculated from these values of VL and sliding distance (SD) using the expressions $[\mathbf{1 4 , 1 5}]$.

$$
\mathrm{WR}=\mathrm{VL} / \mathrm{SD}
$$

where VL is in $\mathrm{cm} 3$ and $\mathrm{SD}$ is in $\mathrm{m}$. The detail experimental conditions are shown in Table 2.

Table. 2. Summary of the pin-on-disc test parameters.

\begin{tabular}{c|c|c|c}
\hline No. & Parameters & Unit & Value (s) \\
\hline 1 & Normal load & $\mathrm{N}$ & $3-5-8-10$ \\
\hline 2 & Sliding speed & $\mathrm{m} / \mathrm{s}$ & $0.15-0.24-0.35-0.48$ \\
\hline 3 & Sliding distance & $\mathrm{m}$ & $432-630-882$ \\
\hline 5 & wear track diameters & $\mathrm{mm}$ & $4-6-8-10$ \\
\hline 6 & Duration of the test & $\mathrm{s}$ & 1800 \\
\hline 7 & Surface condition & - & Dry \\
\hline 8 & Temperature & ${ }^{\circ} \mathrm{C}$ & $25( \pm 1)$ \\
\hline 9 & Relative humidity & $\%$ & $60( \pm 1)$ \\
\hline 10 & Ball diameter & $\mathrm{mm}$ & $17 * 25$ \\
\hline 11 & $\begin{array}{c}\text { Samples dimensions } \\
\text { (diameter*thickness) }\end{array}$ & $\mathrm{mm}$ &
\end{tabular}

(a)

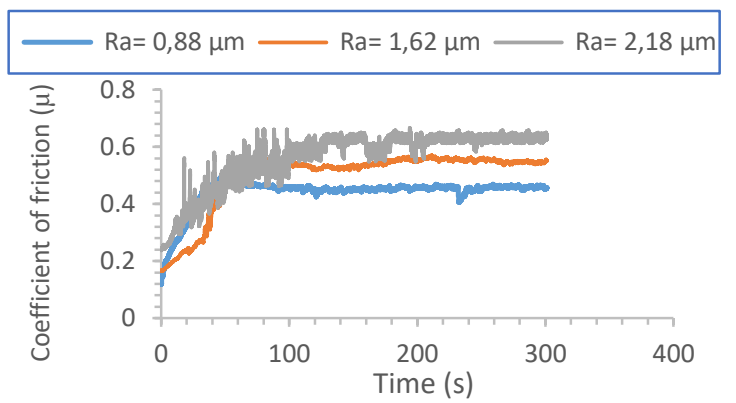

(b)

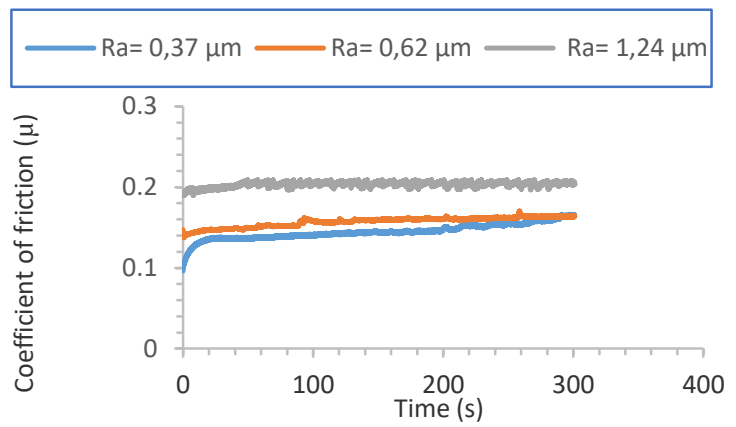

Fig. 1. (a) Coefficient of friction of steel with respect to time at different initial surface roughness. (b) Coefficient of friction of brass with respect to time at different initial surface roughness.

\section{Results and discussion}

\section{Coefficient of friction at different initial surface roughness}

Fig. 1(a) shows the influence of initial surface roughness of steel and brass Fig. 1(b) on the evolution of the average friction coefficient with time. All tests were carried out under a constant normal load $(5 \mathrm{~N})$ and a sliding speed $(0,35 \mathrm{~m} / \mathrm{s})$. The results show that for steel the friction is slightly affected by the initial surface roughness of sample. For brass, the influence of initial surface roughness is more effective. We can note that the value of surface roughness $(\mathrm{Ra})=2,18 \mu \mathrm{m}$ gave highest value in the coefficient of friction 0,56 .

Fig. 2(a) show the coefficient of friction recorded during dry sliding wear of steel and brass at different normal load. tests conducted at $6 \mathrm{~mm}$ wear track. The results show that for steel as the normal load increases from 3 to $10 \mathrm{~N}$, friction coefficient increase from 0.47 to 0.57 and this may be due to increase in the adhesion strength. The trends of these results are similar to the results of E. Rabinowicz [16]. Heat generated at the asperities may decrease the strength of the specimen resulting in more or increased adhesion with disc. The increase of friction coefficient with the increase in sliding can be explained as more adhesion of pin material on the disc. The observations are in agreement with the observation of other researchers [17]. For brass friction coefficient decreases from 0.36 at $3 \mathrm{~N}$ to 0.24 at $10 \mathrm{~N}$. It is apparent that for identical conditions, brass shows much lower friction than steel. The strength of these materials is better at higher shear strain rates [18] which results in a lower real area of contact and a lower coefficient of friction in dry sliding.

(a)

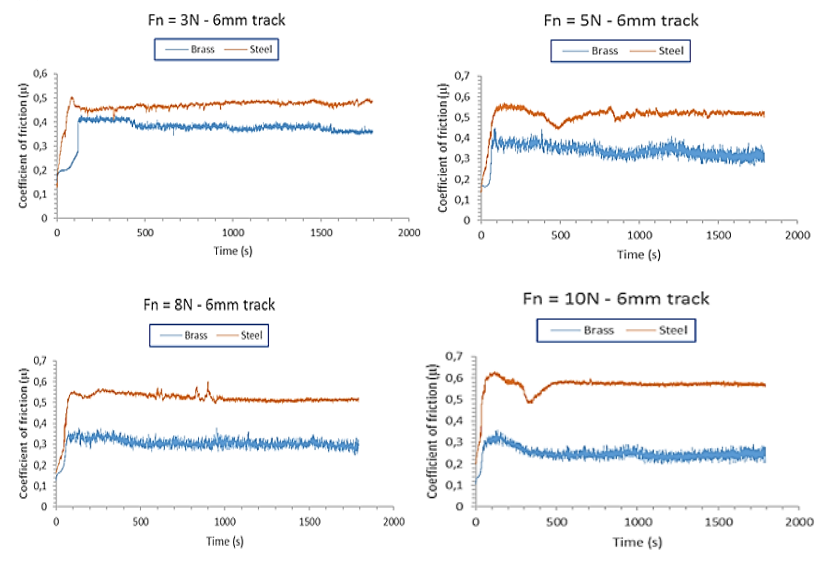

Fig. 2. (a) The friction coefficient curves for: different normal load tests conducted at $6 \mathrm{~mm}$ wear track.

\section{Coefficient of friction at different wear tracks diameters}

Fig. 2(b) show the coefficient of friction recorded during dry sliding wear of steel and brass at different diameters of wear tracks. The results of our test analyzes confirmed that the method of using concentric wear tracks of different diameters provides consistent results for friction and wear on the surface for tracks worn at different diameters [19]. It has been shown that there is little variation in the coefficient of friction curves obtained by wear tracks of different diameters and that there is no obvious relation between the variation of the coefficient of friction and the diameters of the track wear. 


\section{Advanced}

(b)
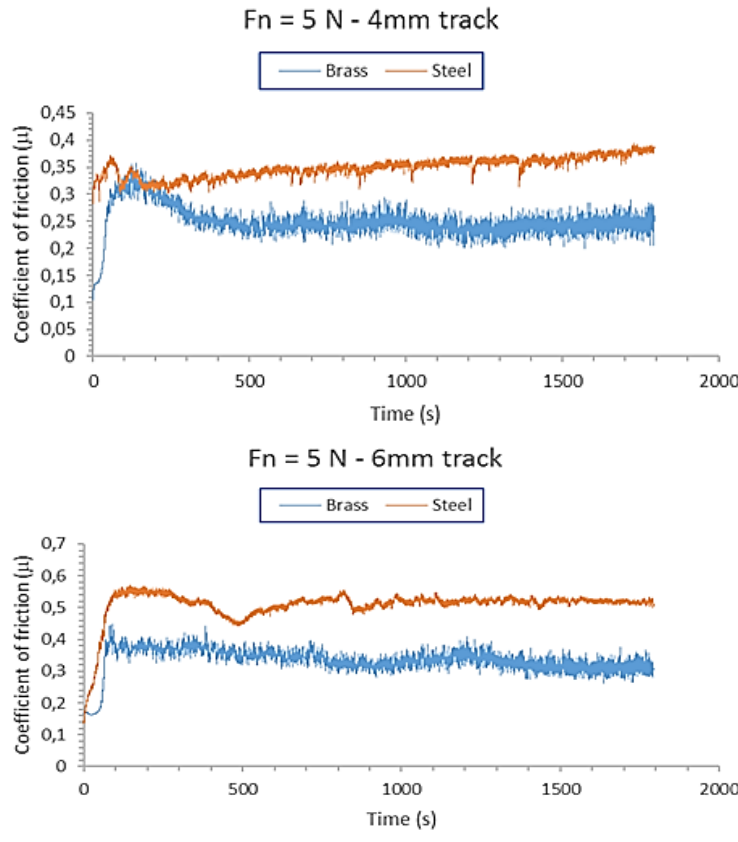

$\mathrm{Fn}=5 \mathrm{~N}-8 \mathrm{~mm}$ track

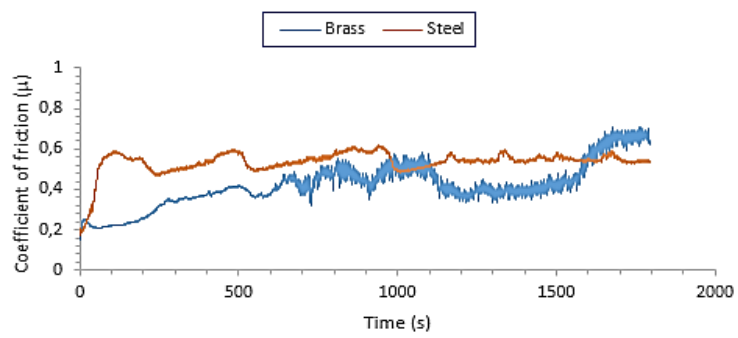

$\mathrm{Fn}=5 \mathrm{~N}-10 \mathrm{~mm}$ track

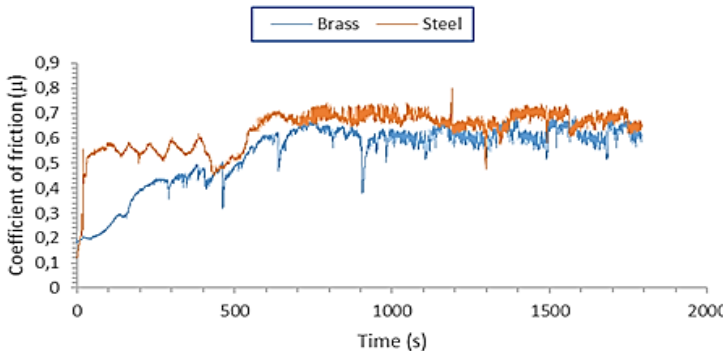

Fig. 2. (b) The friction coefficient curves for: $5 \mathrm{~N}$ tests conducted at different wear track diameters.

\section{Wear loss at different initial surface roughness and normal load}

The plots Fig. 3(a) and Fig. 3(b) show the values of wear loss and wear rate of steel at different initial surface roughness and normal load. The results show that the wear loss and wear rate of steel is increased at high load and high initial surface roughness, whereas wear loss is decreased at low load and low value of initial surface roughness. The higher wear loss and the higher wear rate is obtained at a load of $10 \mathrm{~N}$ and initial surface roughness of 2,18 $\mu \mathrm{m}$. The plots Fig. 3(c) and Fig. 3(d) show the values of wear loss and wear rate of brass at different initial surface roughness and normal load. The results show that wear loss and wear rate of brass is increased at high load and high initial surface roughness, whereas wear loss is decreased at low load and low value of initial surface roughness. On the other hand, wear rate increased at low load and high initial surface roughness, whereas wear rate is decreased at high load and low value of initial surface roughness The higher wear loss is obtained at a load of $10 \mathrm{~N}$ and initial surface roughness of $1,24 \mu \mathrm{m}$.

(a)

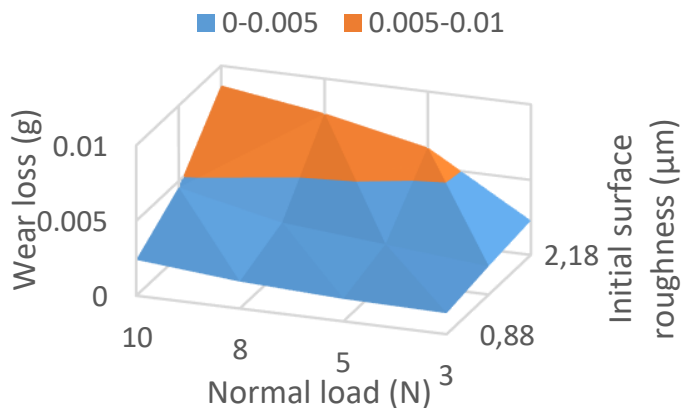

(b)

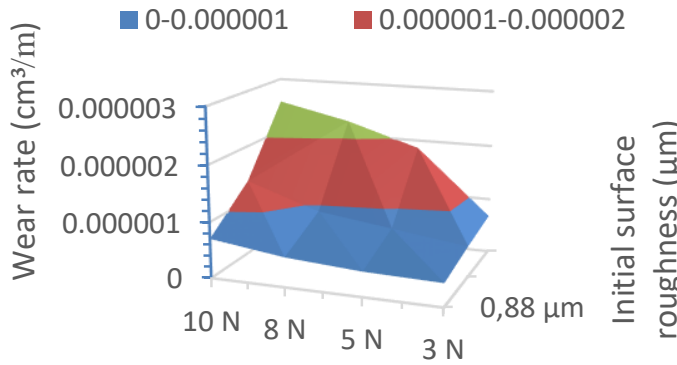

Normal load $(\mathrm{N})$

(c)
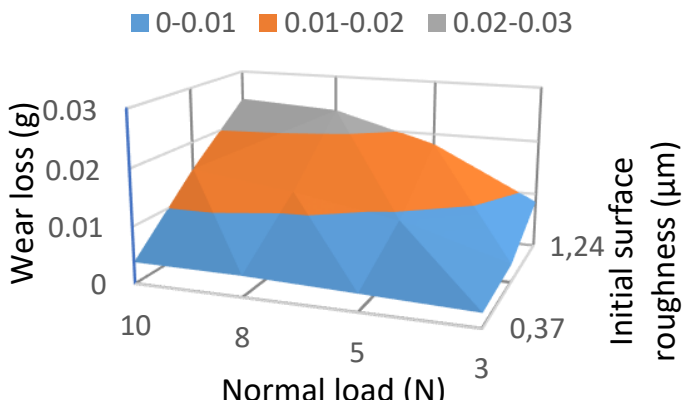

(d)

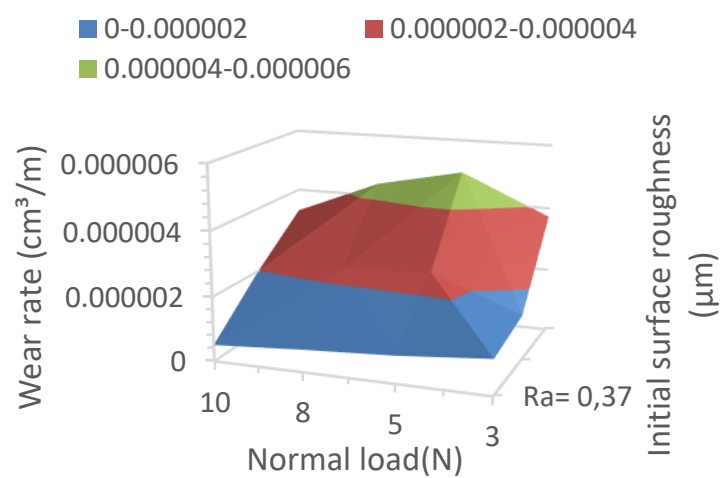

Fig. 3. (a) Surface plot for wear loss of steel versus applied load and initial surface roughness; (b) wear rate of steel; (c) wear loss of brass; (d) wear rate of brass. 


\section{Advanced Materials Letters www. vbripress.com/aml}

Fig. 4 (a,b,c,d) show the variation of track width of steel and brass at different normal load and sliding speed. From this figures it can note that the track width depends on the applied load and sliding speed. The track width rises with load and sliding speed. And it can note that for tow materials at high load $10 \mathrm{~N}$ the track width is slightly affected by sliding speed. And at low load $5 \mathrm{~N}$ the influence of sliding speed on the track width is more effective.

(a)

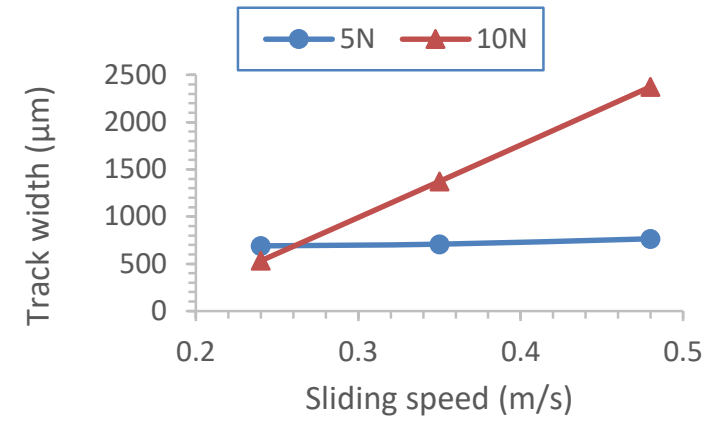

Fig. 4. (a) Variation of Track width of steel at different normal load and sliding speed.

(b)
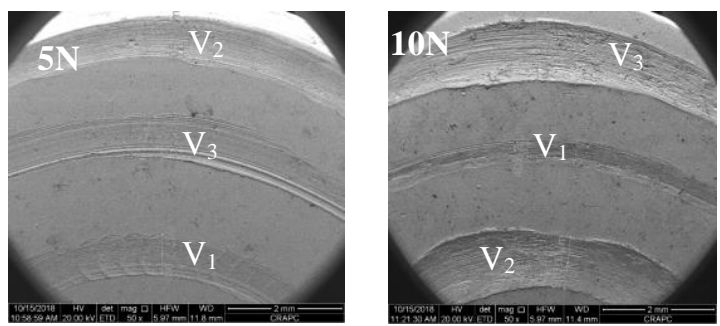

Fig. 4. (b) SEM micrographs of Track width of steel at different normal load and sliding speed.

(c)

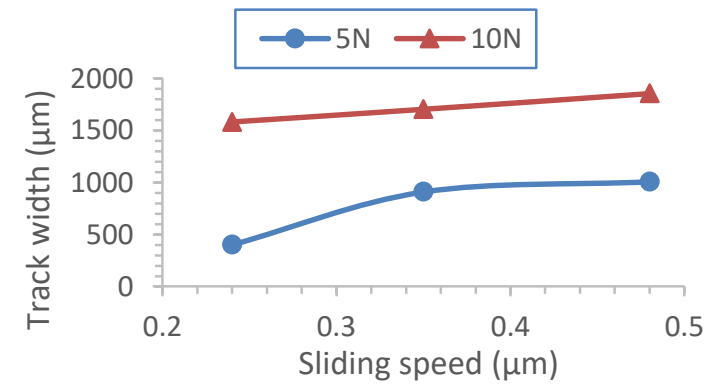

Fig. 4. (c) Variation of Track width of brass at different normal load and sliding speed.

(d)
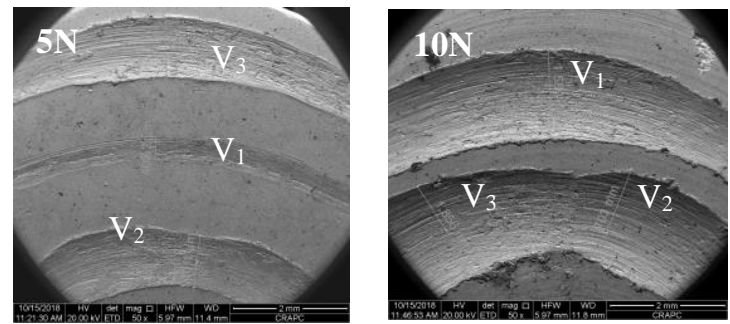

Fig. 4. (d) SEM micrographs of Track width of brass at different normal load and sliding speed.

\section{Analysis of worn surfaces}

Fig. 5 shows worn surface morphology of steel and brass under different loads. Under low load $5 \mathrm{~N}$, there were distinct cut marks and grooves on worn surface, and flake stripping layer in local structure, as shown in Fig. 5 for steel (a) and for brass (c). Judging from this, wear mechanism under such load is abrasive wear and slight spalling wear and some wear debris which has an abrasive action. The responsible for the presence of oxides is wear debris exactly its chemical composition. Experiments have shown that oxidation of debris during friction results in a significant increase in friction coefficient. It should be noted that this phenomenon was also observed in pearlitic microstructures in less load conditions. Spinler [20] reported that the coefficient of friction is relatively high when surfaces are very rough and observed that it increases strongly when the contact surfaces eroded. As the load increased, the width and depth of grooves increased with the range of spalling area also expanded. When the load increased to $10 \mathrm{~N}$, the wear surface experienced severe plastic deformation, and in some parts there were thick peeling pits reached about several hundred microns, as shown in Fig. 5 for steel (b) and for brass (d). Thus, the increase of load will increase the extent and scope of plastic deformation and material peeling, which makes the worn surface become rough, and the wear loss become serious.

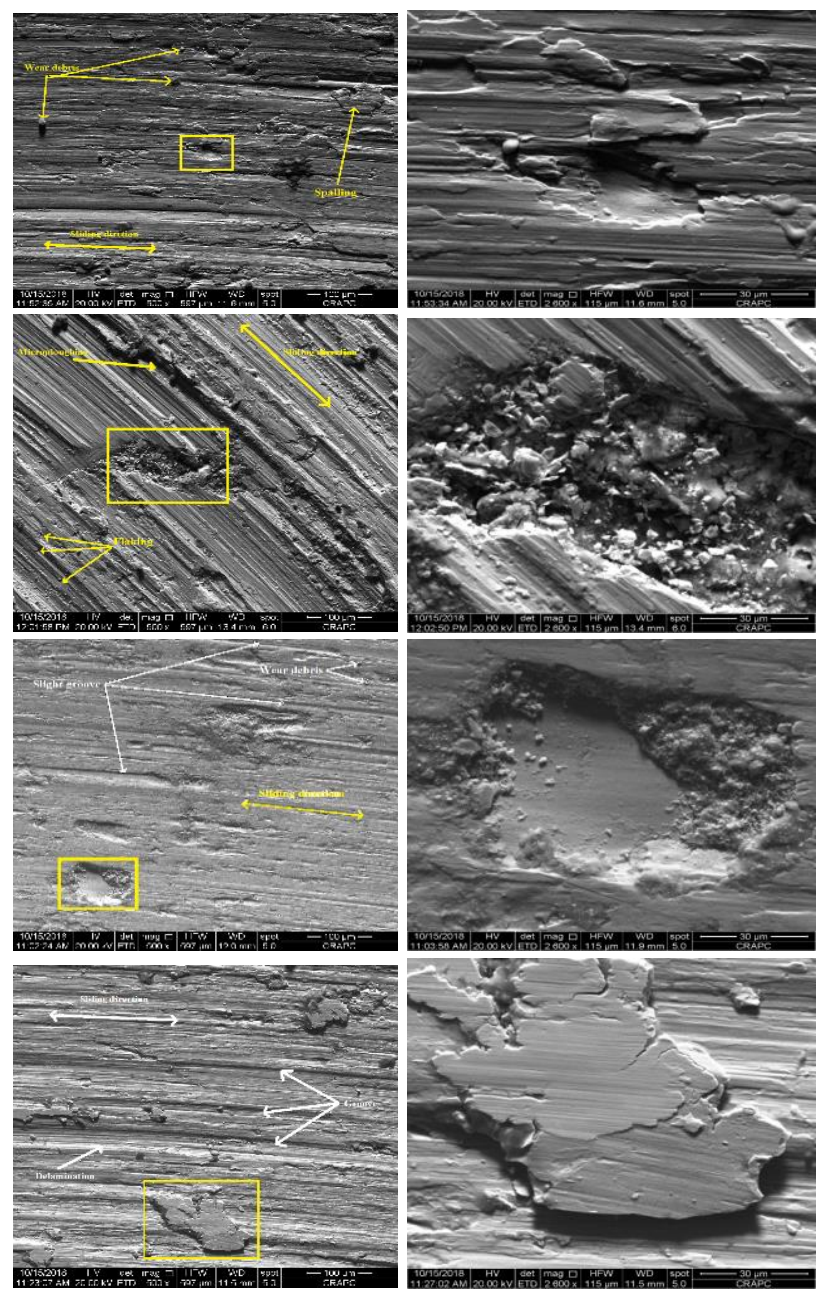

Fig. 5. SEM micrographs of upper specimens at different loads. 


\section{Advanced Materials Letters www. vbripress.com/aml}

\section{Conclusion}

The aim of this research is to evaluate and compare the friction and wear behavior of steel and brass alloy under dry sliding condition. The results provide a detailed characterization of the wear behavior during sliding, the following inferences are drawn from the above study:

The influence of initial surface roughness on the coefficient of friction is more important for brass than for steel. The test clearly indicated increase in wear loss, wear rate, track width with the increase in value of initial surface roughness.

Mainly, during the friction process, friction coefficient of steel increases with the increase of normal load and sliding speed, and at high load, serious spasm occurs on worn surface, this may be due to more adhesion of sliding disc with pin. On the other hand, friction coefficient of brass decreases with the increase of normal load and sliding speed, furthermore it, the values of coefficient of friction of steel are much higher as compared to brass.

Wear loss increase with the increase of normal load and sliding speed, the shear force and frictional thrust increase with the increase in applied normal load and speed and these increments accelerate wear loss. Moreover, wear loss is proportional not only to the distance from the slip but also to the normal load applied.

There exists a strong correlation between track width, wear rate and coefficient of friction in dry sliding wear of steel and brass with positive normal load and sliding speed dependence.

This study indicates the necessity to contribute in giving adequate analysis of surface states, to provide an experimental representation to this phenomenon that has not been sufficiently discovered yet.

\section{Acknowledgements}

Several experiments in this work were conducted outside our laboratory for that, the authors would like to thank: Scientific Research Center of Physico-Chemical Analysis (CRAPC).

\section{Keywords}

Tribological behavior; friction coefficient; wear loss; roughness; wear rate.

Received: 16 October 2019

Revised: 09 November 2019

Accepted: 23 November 2019

\section{References}

1. Katoch, Sanjeev; Sehgal Rakesh; Singh, Vishal; Wear behavior of differently cryogenically treated AISI H13 steel against cold work steel, Proc I Mech E Part E: J Process Mechanical Engineering, Singh first published online: June 9, 2018

2. Matlin, M.M.; Kazankina, E.N.; Kazankin, V.A.; Journal of Friction and Wear, 2016, 37, 320.

3. Coronado, J. J.; Tribol Lett., 2015, 60, 40.

4. Lang, Andrej; Klüppel, Manfred; Wear, 2017, 380, 15.

5. Yi, Yanliang; et al, Wear. 2018, 408, 160.

6. Mishakin, V.V.; Verichev, S.N.; Razov, E.N.; Journal of Friction and Wear, 2017, 38, 286.

7. Kolesnikov, V.I.; Zarif'yan, A.A.; Sychev, A.P.; Kolesnikov, I.V.; Journal of Friction and Wear, 2016, 37, 476.
8. Elhadi, A.; et al, Study of Surface Wear and Damage Induced by Dry Sliding of Tempered AISI 4140 Steel against Hardened AISI 1055 Steel, Tribology in industry, Vol. 38, No. 4 (2016) 475-485.

9. Zambelli, G.; Vincent, L.; Matériaux et contacts, une approche tribologique, Presse polytechniques et universitaires romandes, Suisse, 1998

10. Da Hai, H.; Rafael, M.; Wear, 2001, 249, 626.

11. Ma, X.P.; Wang, L.J.; Liu, C.M.; Subramanian, S.V.; Mater. Sci. Eng., A., 2012, 539, 271

12. Thibault, D.; Bocher, P.; Thomas, M.; J. Mater. Process. Technol., 2009, 209, 2195

13. Li, C.X.; Bell, T.; Corros. Sci., 2006, 48, 2036.

14. Stachowiak, G.W.; Batchelor, A.W.; Engineering Tribology, Butterworth-Heinemann, 2005.

15. Kumar, Hemant; et al, Journal of Nuclear Materials, 2017, 495, 431

16. Rabinowicz, E.; Friction and Wear of Materials, 2nd Edition, Wiley, 1995.

17. Okonkwo, Paul C.; Georgina Kelly b, Bernard F. Rolfe c, Michael P Pereira; Tribology International, 2016, 97, 218.

18. Sheng-cheng ZHANG, Qing-lin PAN1, 2, Jie YAN1, Xing HUANG1, Trans. Nonferrous Met. Soc. China, 2016, 26, 1809.

19. Okonkwo P.C.; et al. Wear 2012, 282, 22.

20. Spinler, G.; Machine Design, Principles and Applications, 1 Static, 2nd Ed. EPFL Press and Chapman \& Hall: Lausanne 2002. 